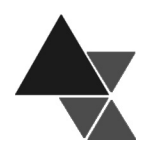

\title{
Segurança Alimentar e Nutricional e controvérsias científicas
}

\author{
Elaine de Azevedo ${ }^{1}$
}

Esta pesquisa conceitual tem o objetivo de estabelecer um diálogo entre o estudo sociológico das controvérsias e a área de pesquisa em Segurança Alimentar e Nutricional (SAN). Para cumprir esse objetivo foram mobilizados autores da Sociologia da Ciência e do Conhecimento Científico que abordam as controvérsias científicas ilustradas aqui com diferentes controvérsias na área de SAN. O estudo aponta a recorrente premissa de que mais ciência não é capaz de promover consensos científicos; destaca a importância da democratização e mobilização do consumidor e aponta estratégias que possam contribuir para estimular a participação e a inserção desse ator na arena de dissolução das controvérsias em SAN.

Palavras-chave: ciência, controvérsias, Segurança Alimentar e Nutricional.

\section{Food and Nutrition Security and Scientific Controversies}

This conceptual research aims to establish a dialogue between the sociological study of controversies and the research in the area of Food and Nutrition Security. To accomplish this goal, authors of the Sociology of Science and Sociology of Scientific Knowledge that address the scientific controversies were used. Their opinions and positions are illustrated here with various controversies in the area of food and nutrition security. The study points to the recurring assumption that more science is not able to promote scientific consensus; it highlights the importance of democratization and mobilization of the consumer and shows strategies that may help to stimulate the participation and inclusion of this actor in the arena of dissolution of controversies in Food and Nutrition Security.

Key-words: science, controversies, Food and Nutrition Security.

\footnotetext{
${ }^{1}$ Doutora em Sociologia Política pela Universidade Federal de Santa Catarina (UFSC). Departamento de Ciências Sociais. Centro de Ciências Humanas e Naturais (CCHN), Universidade Federal do Espírito Santo (UFES). Correspondência: Prédio administrativo do CCHN - Térreo (Primeiro Piso). Goiabeiras - Vitória, ES. CEP 29075-910. Tel. (27) 3019-8410. E-mail. elainepeled@gmail.com.
} 


\section{INTRODUÇÃO}

A pesquisa em alimentação é uma forma de legitimar um alimento fora do seu contexto (natureza) trazido para um laboratório (sociedade). O alimento torna-se, nesse caso, a natureza reinterpretada. Como construir uma verdade sobre tal alimento dentro do laboratório é uma das tarefas da ciência, assim como definir qual o melhor método para inscrever a natureza. É o que Latour ${ }^{[1]}$ chama de construir o centro agindo à distância, através de ciclos de acumulação repetidos. Porém, esse centro nem sempre consegue agregar consensos e pode levar ao seu contrário que é formar controvérsias.

O estudo das controvérsias permite encaixar a ciência em um contexto de atividade humana como outra qualquer que envolve jogos de poder, erros, fragilidades e impotências. Em se tratando de uma ciência voltada à temática da alimentação e riscos, um campo de estudo complexo, repleto de reflexividade e dissensos, a relação controvérsias e Segurança Alimentar e Nutricional (SAN) parece bastante pertinente para compreender as limitações da ciência e para aprofundar a problemática.

Esse artigo conceitual, preparado para compor a discussão do Fórum "Segurança Alimentar e Nutricional: da Biodiversidade às Políticas Públicas", não pretende esgotar essa ampla temática. É um estudo seminal que tem um objetivo pouco ambicioso: mostrar como o estudo sociológico das controvérsias dialoga com a pesquisa em SAN. A emergente área de pesquisa em SAN pode se fortalecer e se beneficiar de tal conhecimento ao inserir elementos sociológicos na sua abordagem, bem como nos fóruns das controvérsias que instituições voltadas à SAN vêm promovendo.

Nos anos de 2012 e 2013, o Conselho Nacional de Segurança Alimentar e Nutricional (CONSEA) realizou duas mesas sobre controvérsias dos agrotóxicos e dos transgênicos. Entretanto, é preciso ressaltar que esses fóruns não enfocaram centralmente a temática das controvérsias. A partir da fala de diferentes especialistas que utilizaram pesquisa e dados sobre os impactos negativos do uso de agrotóxicos e da liberação dos transgênicos no Brasil, estabeleceram-se fóruns de consenso que consolidaram o posicionamento desfavorável do CONSEA sobre tais tecnologias agrícolas. Esta constatação não pretende desqualificar essas importantes iniciativas do Conselho, nem questionar seu ético e necessário posicionamento, mas ressaltar a importância de conhecer as especificidades que rondam o tema das controvérsias da ciência que justifica a relação proposta no artigo.

Para cumprir o objetivo proposto foram mobilizados autores da Sociologia da Ciência e do Conhecimento Científico que abordam as controvérsias científicas e alguns estudos na área de alimentação e SAN que podem ajudar a embasar tal relação.

\section{O estudo das controvérsias em Segurança Alimentar e Nutricional (SAN)}

As controvérsias estão presentes desde o início da história da ciência e pode-se dizer que elas foram centrais para seu desenvolvimento na medida em que as incertezas geram necessidade de outros estudos e promovem debates e arenas de conciliação e disputas. Os primeiros estudos sobre as controvérsias científicas datam da década de 1990, mas ainda se mostram atuais para compreender como os mesmos moldam o desenvolvimento da ciência contemporânea.

O estudo das controvérsias é uma estratégia metodológica para explorar as sinuosas e nem sempre claras dimensões sociais e políticas da ciência. Tal estudo ajuda a investigar as metáforas, os embates e os pressupostos inerentes a discursos e resultados aparentemente neutros [2]. Tal abordagem não se preocupa com o determinismo ou a veracidade das pesquisas, mas em analisar como as verdades atingem tal status e em interpretar os processos ativos através dos quais os cientistas dão sentido aos riscos. O processo social de construção da ciência considera a relação entre os cientistas, a origem dos financiamentos e o perfil das instituições que promovem a pesquisa, além da maneira como os cientistas elegem determinados temas como tópicos de análises ${ }^{[3]}$.

Callon [4] mostra que esse estudo contribuiu para questionar a premissa de que a ciência e a tecnologia não sofrem outra influência que não a intelectual. Para esse autor, as controvérsias são "impuras e heterogêneas" e só podem ser compreendidas trazendo-se para o campo de análise "os interesses, as estratégias e as relações de reação que não param na porta do laboratório" e que perpassam a ciência e a pesquisa (p. 19).

As controvérsias na ciência têm implicações sociais, políticas e econômicas e caracterizam desacordos entre especialistas das áreas científica, 
médica ou técnica. Disputas entre peritos provocam dificuldades para a implementação de políticas e os confrontos são, algumas vezes, rancorosos e insolúveis. Para esses autores, o perito neutro, desinteressado e objetivo - perfil construído dentro da própria rede da ciência - foi tradicionalmente designado como o árbitro racional e autorizado para resolver disputas públicas que se sobrepõem a assuntos técnicos e científicos. Entretanto, o ultrapassado ideal de apelo aos fatos e sua interpretação por peritos acreditados foi corroído pelas óbvias limitações dos mesmos e do seu conhecimento em solucionar assuntos de controvérsias públicas. Existe agora uma difundida percepção pública de que os peritos não são infalíveis em virtude do acesso especialista a metodologias científicas de rigor que poderiam garantir sua objetividade. Sabe-se que uma aparente opinião desinteressada pode estar influenciada por considerações profissionais, econômicas ou políticas ${ }^{[5]}$.

As controvérsias científicas revelam a influência da ciência em todas as instâncias do cotidiano, o sistema de distribuição de recursos e o locus do poder e do controle expondo um campo de batalha e de valores contestados na sociedade. Seu estudo enfatiza as tensões entre necessidades individuais e grupais, traz à tona a relação ambígua entre as diversas instituições sociais (mídia, organizações públicas e privadas, sistemas judiciais e regulatórios) e a ciência [6,7]. Existem insatisfações e divergências científicas uma vez que os cientistas representam uma variedade de grupos de pressão e instituições interessados nos temas de pesquisa.

Como esperado, na análise das controvérsias na área da SAN no Brasil, também percebem-se disputas internas, ou seja, dentro do próprio meio científico sobre evidências no campo da segurança e da eficácia de determinadas tecnologias e insumos agrícolas. Entretanto, novos embates devem continuar a emergir nas diferentes áreas de saúde, agricultura, economia e meio ambiente. Isso porque o estudo da SAN interferiu até mesmo no conceito de alimentação saudável - que passou a incorporar o termo "adequada" e os componentes culturais e socioambientais. Além disso, os princípios e objetivos da SAN são rizomáticos e englobam quase todas as questões que vêm se destacando como polêmicas nesse campo: o uso dos contaminantes químicos no sistema agroalimentar (não só agrotóxicos, mas fertilizantes, aditivos sintéticos, drogas veterinárias), a questão que envolve a superioridade dos alimentos orgânicos, os benefícios do alimento local e das dietas culturalmente definidas, os processos tecnológicos como a irradiação dos alimentos, as repercussões negativas da produção animal industrial e do consumo excessivo de carne, o uso seguro das biotecnologias (transgênicos, nanotecnologia), a fortificação dos alimentos, só para citar alguns exemplos.

Nelkin [ [ destaca cinco tipos de controvérsias científicas que não são puros, mas sujeitos a contaminação e influências mútuas. Como é essa tipologia e como ilustrá-la a partir das controvérsias na área de SAN?

O primeiro tipo são aquelas controvérsias que têm implicações sociais, morais e religiosas colocando cientistas e especialistas debatendo com grupos que barram o desenvolvimento de certas pesquisas por causa da ameaça a suas convicções morais. Esse tipo pode ser ilustrado pela discussão que envolve a restrição da carne na perspectiva da preservação dos direitos dos animais. O segundo tipo de controvérsia coloca em estado de tensão valores ambientais e as prioridades políticas e econômicas; como exemplo, o processo de regularização dos transgênicos no Brasil. O terceiro tipo de controvérsia considera riscos à saúde relacionando-os às práticas industriais e comerciais. A questão da liberação dos agrotóxicos no país e a minimização da importância dos estudos de riscos à saúde frente aos interesses das multinacionais de insumos agrícolas ilustra esse tipo de controvérsia. $\mathrm{O}$ quarto tipo revela embates entre expectativas individuais e objetivos sociais ou comunitários. São exemplos, as polêmicas que envolvem $\mathrm{O}$ enriquecimento das farinhas com ácido fólico, o uso de iodo sintético no sal e o uso de cloro na água - mais expoentes fora do Brasil. O quinto tipo de disputas refere-se a conflitos relacionados a questões de equidade na distribuição de recursos para produzir ciência, especialmente nas instituições públicas. Para ilustrar essa tipologia, destaca-se a discrepância entre o orçamento disponibilizado para pesquisa na área de agricultura familiar e na área do agronegócio na Empresa Brasileira de Pesquisa Agropecuária (EMBRAPA), bem como seu visível interesse comercial no desenvolvimento dos transgênicos. As alianças entre os departamentos de agronomia de universidades públicas e as multinacionais produtoras de insumos agrícolas também influenciam no perfil das pesquisas agrícolas e no acirramento das controvérsias nesse campo. O resumo dos tipos de controvérsias encontra-se no Quadro 1. 
Quadro 1. Resumo dos tipos de controvérsias científicas

\section{Tipos de controvérsias científicas}

Controvérsias com implicações sociais, morais e religiosas

Controvérsias que tencionam valores ambientais e prioridades políticas e econômicas

Controvérsias que consideram riscos à saúde

Controvérsias reveladoras de embates entre expectativas individuais e objetivos sociais ou comunitários

Controvérsias relacionadas a conflitos referentes à equidade na distribuição de recursos para produzir ciência nas instituições (especialmente públicas)

Fonte: Nelkin ${ }^{[6]}$.

Dascal ${ }^{[8]}$ também se preocupou em analisar as controvérsias e o Quadro 2 resume suas características. Uma primeira característica levantada pelo autor é que as controvérsias tendem a gerar problemas secundários, desdobrando-se em extensão e profundidade. Desse modo, as controvérsias são frequentemente atreladas a certa imprevisibilidade - não se sabe exatamente onde elas podem chegar e quais objeções do oponente elas podem revelar. Se a controvérsia inicia, por exemplo, com a questão do impacto da carne de animais afetados pela encefalopatia bovina espongiforme sobre a saúde humana, pode terminar com o questionamento do sistema de produção animal ou revelar o despreparo das agências reguladoras e sanitárias diante de riscos alimentares. Com frequência, pode ocorrer que, ao se adotarem os "novos" problemas como prioritários, a causa inicial da controvérsia é deixada de lado e fica inconclusiva.

Quadro 2. Resumo das características das controvérsias

Geradoras de problemas secundários

Atreladas a certa imprevisibilidade

Questionam pressupostos científicos, factuais, metodológicos ou conceituais dos seus oponentes

Promovem crítica irrestrita aos adversários e defesa acirrada aos aliados

Ampla abrangência e inserção em dimensões interdisciplinares

Polêmicas e geradoras de inovações e discussões criativas

Caráter temporal

Fonte: Dascal ${ }^{[8]}$.

Outra característica das controvérsias é que os oponentes do problema tendem a questionar a própria finalidade da atividade científica e os pressupostos factuais, metodológicos ou conceituais dos seus "rivais". Essa característica mescla-se com uma terceira. Durante uma controvérsia, os oponentes assumem o duplo dever de criticar seus adversários e suas posições e defender seus aliados e suas próprias teorias. Nas controvérsias que envolvem a pesquisa sobre a relação soja e saúde humana explorada por Azevedo [9], destacam-se a polêmica arena de embates entre os dois grupos de pesquisadores (a favor e contra a soja), as coalizões formadas pelos pesquisadores que defendem o grão e suas estratégias de divulgação e validação de seus estudos. A reação que esse estudo causou em um pesquisador estadunidense foi publicada na Revista de Saúde Pública [10] na forma de cartas entre pesquisadores e ilustra bem essa característica.

Além disso, percebe-se que os cientistas "pró e contra transgênicos" usam, com frequência, os mesmos tipos de estudos reducionistas para evidenciar seus 
pontos de vista, sem discussões que remetem ao contexto social de produção da ciência. Ressalta-se que tais estudos, baseados em aspectos nutricionais (estudando o impacto da tecnologia sobre o valor nutricional de alimentos) ou toxicológicos (buscando a relação entre os alimentos geneticamente modificados e a saúde de animais de laboratório), raramente conseguem promover o consenso na área de SAN. Concorda-se com Nelkin [6], para quem a argumentação racional, baseada em dados científicos e supostamente neutros e objetivos, interfere pouco na dissolução das controvérsias.

Dascal [8] aponta também a abrangência das controvérsias o que as levam, frequentemente, a se inserir em dimensões interdisciplinares. O caso dos alimentos locais ilustra bem essa questão. A questão do gasto energético relacionado ao transporte de alimentos (food miles) que embasa essa discussão ambiental pode levar a questões muito mais complexas, relacionadas a formas diferenciadas de comercialização dos agricultores familiares no âmbito da Economia Agrária e Desenvolvimento Rural passando pelas discussões que envolvem a identidade cultural de um povo e a territorialidade dos hábitos alimentares.

As controvérsias têm a capacidade de revelar divergências em relação ao significado dos conceitos, métodos e fatos aceitos até o presente e, por isso, são capazes de gerar inovações e discussões criativas (e extenuantes). Analisando-se, por exemplo, a quantidade de estudos científicos e debates em diferentes arenas sobre as controvérsias que circundam os Organismos Geneticamente Modificados (OGMs), essa característica fica muito evidente. O próprio conceito de SAN sofreu diversas influências de controvérsias científicas que o tornou uma construção permanente, aberta a novos significados e sentidos. E como se encerram as controvérsias? Dascal [8] refere-se aos ajustes dialógicos e ao consenso como a melhor maneira de finalizar uma controvérsia. Em muitos casos, no âmbito da negociação, as controvérsias são encerradas, mas não significam que são necessariamente resolvidas. Isso aponta o caráter temporal das controvérsias. Quando as controvérsias se encerram, os cientistas e especialistas que continuam defendendo seu ponto de vista contrário são desconsiderados ou deixam a arena da negociação (ou da ciência como um todo). Questiona-se se o caso dos transgênicos no Brasil não está caminhando para essa condição. Apesar do contínuo interesse de algumas instituições promotoras de SAN em manter a discussão sobre a liberação dos OGMs no Brasil, como por exemplo, o CONSEA nacional e algumas associações de agricultores e consumidores, Guivant [11] sinaliza esse atual momento dos transgênicos no Brasil como já sendo de pós-controvérsias, no qual a coalizão contrária à liberação dos mesmos vem perdendo força e espaço político ${ }^{2}$.

Para Nelkin [6], os meios para dissolver controvérsias dependem da natureza de sua percepção. Se a disputa foca em questões relacionadas ao controle político do desenvolvimento e a aplicação da ciência, reflete interesses competitivos, negociações e medidas compensatórias que podem reduzir o conflito e levar a uma resolução. Mas quando princípios morais estão em jogo, argumentos técnicos nem sempre afetam a posição dos protagonistas. Para a autora, a resolução dos conflitos reflete necessariamente o poder político dos interessados que competem na arena das controvérsias e a argumentação racional dos peritos, baseada em dados científicos e supostamente neutros e objetivos, interfere menos na sua dissolução. Quando uma controvérsia termina a parte "vencedora" é aquela que resistiu a maioria ou a todos os ataques e conseguiu persuadir a sociedade (ou pelo menos seus membros mais influentes ou renomados nos meios científico e político) sobre seus argumentos.

No quadro de pesquisa em SAN coexistem, com frequência, as duas forças mencionadas por Nelkin: os interesses competitivos da ciência e os princípios morais. As forças que estão em jogo são os interesses das indústrias agroalimentares ou de empresários, as associações de agricultores ou populações rurais vulneráveis, as Organizações Não Governamentais (ONGs) e instituições públicas, os especialistas associados a todas essas instituições e, de forma não tão evidente, o consumidor leigo. $\mathrm{O}$ que tende a prevalecer são ideias de um grupo da ciência mais fortalecido em termos de reconhecimento ou poder econômico.

Assim como podem ser ignorados ou, simplesmente, esquecidas, as controvérsias podem também ser mantidas. A posição de Latour ${ }^{[1]}$ coincide com a de Nelkin [6,7] sobre o caráter político que envolve a resolução das controvérsias, mas todos acreditam que as controvérsias terminam num

\footnotetext{
2 Essa hipótese é o cerne de um projeto de Guivant em andamento, apresentado ao CNPq em 2013 sob o título "Transformações nas alianças, regulação e mercado para os produtos transgênicos e não transgênicos: o fechamento da controvérsia?".
} 
determinado momento. Para Latour [1], uma controvérsia se torna um fato indiscutível quando é possível construir uma rede coesa de aliados em torno da polêmica, que passa, então, a ser percebida como uma caixa preta.

Ao contrário de outros países onde as pesquisas e as controvérsias científicas constituem material base para fomentar a legislação e a regulação das inovações tecno-científicas, as pesquisas na área de alimentação e tecnologia realizadas no Brasil (muitas vezes, sob condições de limitações metodológicas) são utilizadas para confirmar os argumentos que determinados grupos sociais, políticos ou econômicos desejam legitimar [12]. Essa afirmação permite levantar outra caraterística das controvérsias não mencionada pelos autores acima: sua dimensão cultural e geográfica. Ou seja, uma controvérsia pode não ser considerada ou legitimada da mesma forma em todos os países.

Guivant \& Macnaghten [13] mostram que no caso do contexto brasileiro, o conhecimento científico ainda é percebido como uma estratégia confiável e ressaltam a carência de formas institucionais de engajamento público como parte de uma governança científica, uma forma de "controvérsia sem democratização” (p. 96) como pode ser percebido no debate brasileiro sobre transgênicos:

(...) para entender o debate brasileiro sobre OGMs, é preciso entender a persistência da cultura política brasileira caracterizada como inflexivelmente elitista e tradicional, e onde mesmo a ação de partidos políticos e esfera pública (incluindo movimentos sociais) permanecem distantes a vida cotidiana da maioria das pessoas. (...). O conflito em relação aos OGMs deixou o público indiferente e $O$ regime de avaliação tecnocrático intacto. É necessário considerar aqui os diferentes contextos de transparência e accountability que existem no Brasil [13] (p. 9798).

Os autores seguem na discussão e defendem que muitos outros riscos desconhecidos não são incorporados como perigo no Brasil e citam o exemplo dos agrotóxicos [13]. Mesmo sob um controle regulatório crescente, a informação sobre os problemas da contaminação dos pesticidas continua limitada e pouco disseminada na sociedade. O fato é que o relativo silêncio, a falta de debate e a tranquilidade da população brasileira diante de riscos alimentares pode indicar não uma confiança nas agências reguladoras nacionais, mas talvez "uma atitude de resignação ou indiferença frente aos possíveis riscos junto com o desconhecimento de sua dimensão" "14] (p. 107). Dessa forma, Guivant \& Macnaghten [13] defendem que a sociedade brasileira - incluindo cientistas, políticos e público - não parece demonstrar interesse no debate em torno dos riscos e benefícios das tecnologias emergentes (ou mesmo daquelas não tão novas como os pesticidas). Finalizando, o estudo destaca outro aspecto importante, comparando a desqualificação da categoria "público" com a categoria "consumidor" que também pode influenciar na construção de consensos diante de riscos relacionados aos alimentos:

A marginalização do "consumidor" como um ator importante no imaginário político pode ser explicada pela associação do termo consumidor com uma elite da população brasileira. Então, novamente vemos uma clara diferença entre a maneira como ONGs na Europa, em particular, visavam aos consumidores enquanto cidadãos, e no Brasil, onde o consumo vem sendo considerado em menor grau como espaço para a construção de direitos de cidadania (p. 98).

\section{O papel do consumidor leigo nas controvérsias em Segurança Alimentar e Nutricional (SAN)}

Spaargaren ${ }^{[15]}$ aponta outro aspecto relevante à discussão que envolve cidadania e consumo quando afirma que, ao assumir o papel de cidadão, os indivíduos expressam preocupações com a conservação ambiental e com a SAN, mas como consumidores, não colocam, com frequência, essas afirmações em prática e optam pelos produtos de menor valor. Este é um "velho conhecido" fenômeno da psicologia social que analisa a lacuna presente entre as atitudes e o efetivo comportamento dos indivíduos. Tal lacuna é investigada sociologicamente sob as premissas da falta de empowermet do consumidor e sob a perspectiva da emergência de uma sociedade civil global, envolvida com o monitoramento e a politização do consumo.

As práticas ambientais dos leigos em países como o Brasil e outros países que não completaram seu desenvolvimento pleno e que se preocupam em alcançar tal desenvolvimento a partir de premissas econômicas, ainda estão longe de ser compreendidas. O movimento ambiental é marcado pelo conflito de interesses e por polarização entre visões de mundo e 
perspectivas culturais. Apesar de existirem estudos que abordam a crescente adoção de práticas ambientais coletivas no Brasil realizadas através de redes, associações e coalizões [16], não foram encontrados estudos recentes sobre práticas ambientais efetivamente assumidas (ou não) pelos brasileiros. $\mathrm{Na}$ área de SAN não é muito diferente. No caso do consumo de alimentos orgânicos, por exemplo, ao inquirir os informantes, os estudos normalmente limitam-se a considerar o seu discurso (ou sua intenção ou propensão a consumir tais alimentos). Os estudos não oferecem elementos relativos à sua efetiva prática e não abordam os consumidores que desqualificam essa prática, nem suas razões para tal.

Irwin [3] defende uma ciência sem monopólio da racionalidade, mas reflexiva e atenta a uma redefinição de si mesma e que inclui a deliberação institucional e os esforços de uma nova organização política e ambiental.

Uma possiblidade de democratizar as controvérsias dentro de uma nova organização reside no modelo de subpolítica de Beck [17], uma forma de governança que coloca a política na mão dos cidadãos e que dialoga com a abordagem da politização do consumo. Esse modelo deliberativo inclui agentes externos ao sistema político, coletivos ou individuais, que exercem influência sobre as decisões sociais e estabelece fóruns de negociação entre governo e agentes políticos, instituições privadas, sindicatos e o público em geral. Nessa arena de negociação, dúvidas são acolhidas, medidas preventivas podem ser tomadas e as controvérsias são trazidas como pública de forma a preparar o terreno para ações políticas e novas agendas. $\mathrm{O}$ consumidor inserido nesse debate pode vir a assumir um papel importante nos processos de resolução das controvérsias.

Como já mencionado, mais ciência não pode resolver os impasses que envolvem a SAN e tendem a exacerbar os dissensos. A informação necessária "não é sobre o conteúdo da ciência, é sobre a relação entre os especialistas e o político, os meios de comunicação e o público" ${ }^{[18]}$ ( p. 196).

\section{CONSIDERAÇÕES FINAIS}

Como estimular esse consumidor a participar e como promover seu empowerment e sua inserção nos debates sobre as controvérsias em SAN no Brasil? Quais são os outros atores que devem ser inseridos nos debates? Essas deveriam ser questões centrais para as instituições promotoras de SAN interessadas em processos de diluição de controvérsias como, por exemplo, os CONSEAs nacionais, estaduais e municipais.

O consumidor leigo deve assumir, gradativamente, um papel de maior destaque, como já acontece na arena de controvérsias científicas em outros países. A reflexividade moderna, que orienta as escolhas também no consumo, e o elemento propulsor deste novo ator da arena de construção social do conceito de SAN.

Guivant ${ }^{[19]}$ ressalta a importância de fomentar estudos sobre a percepção pública da ciência para captar a aceitação ou rejeição dos consumidores dos transgênicos. Para além dos OGMs, tais estudos devem avaliar atitudes e percepções de qualquer tecnologia que afete a SAN dos consumidores. Futuros e necessários estudos de perfil do consumidor de alimentos devem se concentrar nos meios através dos quais este ator poderá exercer seu papel político e influenciar na construção do conceito de alimento saudável e adequado, junto às forças do mercado. Muitas questões perpassam esse complexo e multifacetado campo do consumo que merece ser compreendido em futuras pesquisas. Estas pesquisas-ação não devem somente buscar conhecer a realidade, mas também problematizar, junto aos consumidores, as questões pertinentes aos riscos da alimentação e enfatizar seu papel em promover SAN.

Nestle [20] se debruça sobre o contexto da indústria de alimentos influenciando as diretrizes da SAN e aponta a educação e a informação como estratégias centrais para fortalecer as ações dos consumidores na escolha de alimentos saudáveis.

Também para Spaargaren [15], a informação tornou-se constitutiva para práticas de consumo sustentável que apresentam um caráter de cunho político. Segundo esse autor, para que o consumidor possa fazer suas escolhas é preciso explorar novos formatos de oferta de produtos e informações através de rotulagens simplificadas, esquemas de certificação e grifes confiáveis, “(...) in a consumer oriented way)" (p. 155).

\section{Mas quais são as formas mais efetivas de informar o consumidor de alimentos?}

Considerando que na medida em que a informação circula, as relações de poder se modificam, 
cada vez mais se valoriza a estratégia de veicular informação através da rotulagem e certificação dos alimentos. Institutos de defesa do consumidor (como o Instituto Brasileiro de Defesa do Consumidor - IDEC, no Brasil e o Public Citizen, nos EUA) têm incentivado e defendido essas ferramentas como um direito e como estratégia de democratização do consumidor no processo decisório que envolve controvérsias em SAN. Rotulagens e selos de certificação já vêm sendo utilizados para informar o valor nutricional de produtos industrializados $\mathrm{e}$ indicar o modelo produtivo (a exemplo dos orgânicos). Estes sistemas de comunicação funcionam não só como apelo de marketing educativo, mas como forma de garantir os direitos do consumidor - direito de acesso à informação e de conhecer a origem de seus alimentos. Um rótulo que informa quem o consumidor está apoiando com sua compra pode tornar-se uma importante ferramenta de rastreabilidade e de promoção de SAN.

Paralelo ao esquema de rotulagem dos alimentos controversos, muitas vezes difícil de implementar (como no caso dos transgênicos), pode-se pensar em sistemas "positivos" de rotulagem e certificação que estimulem o consumo de alimentos seguros e adequados.

A mídia é outro agente que pode contribuir para a promoção de uma alimentação segura, assim como já vêm atuando em campanhas antitabagistas e de controle do consumo de álcool. As informações veiculadas pelos diferentes meios de informação podem ajudar a promover a reflexividade e a construir um consumidor mais consciente e ativo. É possível prever acirrados e polêmicos debates que campanhas publicitárias do "tipo antiaçúcar" podem gerar nas áreas da saúde e dentro da poderosa e influente indústria de alimentos.

Para formar uma opinião sobre um alimento saudável ou de risco (ou qualquer outra decisão que exija bases científicas), o leigo precisa ter conhecimentos suficientes sobre questões técnicas. $\mathrm{Na}$ maioria das vezes tal conteúdo é de difícil compreensão para o consumidor. Um primeiro desafio é traduzir o conhecimento científico de forma a torná-lo acessível e esse é um papel do jornalismo e dos meios de comunicação que, de alguma forma, tem feito isso. Revistas semanais utilizam-se frequentemente de estudos acadêmicos para ilustrar artigos sobre temas que envolvem controvérsias científicas. Apoiar e “alimentar" - usando uma boa metáfora de SAN - o jornalismo ambiental e científico estimula também a construção de consumidores mais atentos e conscientes.

Também é importante desenvolver formas de organização que promovam os interesses dos consumidores, além de novas arenas para ações políticas voltadas para os atores do mercado, consumidores-cidadãos e práticas de comportamento sustentáveis. Os fóruns de SAN constituem excelentes espaços para tais ações.

A democratização do consumidor com base na informação sobre a produção, sobre a prática da ciência e sobre a desmonopolização do sistema perito é uma estratégia importante para revelar a nova condição deste ator e novas ferramentas de consulta pública. A época na qual a visão do público frente aos riscos era dispensada como irrelevante está dando lugar a um maior engajamento do leigo com a ciência [21].

A abordagem das controvérsias não implica em uma atitude anticiência, nem questiona a capacidade ou idoneidade dos cientistas que devem ser tratados como qualquer profissional passível de acertar ou errar. A ciência é uma atividade humana inseparável da sociedade e dos interesses humanos por reconhecimento institucional e financiamento. Assim, como é compreensível o fato de que a indústria agroalimentar se utiliza desse conhecimento para tornar seu produto atraente e vender mais, uma vez que um parecer sobre saúde é um excelente marketing para alimentos. Não parece produtivo julgar, mas entender que isso está dentro das regras do jogo da ciência cujos riscos fazem parte do contrato com a contemporaneidade.

A pergunta "em quem acreditar?" não leva a nada, pois trata somente de cientistas em desacordo [18]. Para abordar qualquer decisão que exija referências científicas, não é suficiente ter conhecimento sobre questões técnicas ou pesquisas reducionistas "pró e contra" determinada tecnologia ou risco. O que os leigos e especialistas também precisam conhecer para definir se um alimento é saudável e seguro são as relações dos bastidores da ciência que o campo das controvérsias se preocupa em revelar. 


\section{REFERÊNCIAS}

[1] Latour B. Ciência em Ação: como seguir cientistas e engenheiros sociedade afora. São Paulo: UNESP; 2000.

[2] Pinch TJ. Scientific controversies. In: Jasanoff S. (Eds). International encyclopedia of the social and behavioral sciences. Amsterdam: Elsevier; 2002.

[3] Irwin A. Sociology and the Environment. A critical introduction to society, nature and knowledge. London: Polity Press; 2001.

[4] Callon M. The Sociology of an Actor-Network: The Case of the Electric Vehicle. In: Callon M, Law J, Ri A. (Eds). Mapping the Dynamics of Science and Technology. London: The Macmillan; 1986.

[5] Martin B, Richards E. Scientific Knowledge, Controversy, and Public Decision-Making. In: Jasanoff S, Markle GE, Petersen JC, Pinch, T. (Eds.). Handbook of Science and Technology Studies. Newbury Park, California: Sage; 1995.

[6] Nelkin D. Science controversies: the dynamics of public disputes in the United States. In: Jasanoff S, Markle GE, Peterson JE, Pinch T. (Eds.). Handbook of science and technology studies. Thousand Oaks/London/New Delhi: Sage; 1995.

[7] Nelkin D. Science, technology, and political conflict: analyzing the issue. In: Nelkin D. (Ed.). Controversy: politics of technical decisions. Beverly Hills/London/New Delhi: Sage; 1984

[8] Dascal M. The study of controversies and the theory and history of science. Science in Context. 1998;11:147-154.

[9] Azevedo E. Riscos e Controvérsias na construção do conceito de Alimento Saudável: o caso da soja. Rev Saúde Públ. 2011;45(4):781-8.

[10] Understanding the health effects of soyfoods and unfair characterization of promotional efforts by the soyfood industry. Rev Saúde Públ. 2011;45(5).

[11] Guivant JS. Governance of GMOs and the constraints for a definition of the public arena. In: Dasgupta S. (Ed.). Understanding the Global Environment. New Dehli: Pierce Education; 2009 .

[12] Guivant JS. Transgênicos e percepção pública da ciência no Brasil. Revista Ambiente \& Sociedade. 2006;9(1):81-103.
[13] Guivant JS, Macnaghten P. O mito do consenso: uma perspectiva comparativa sobre governança tecnológica. Revista Ambiente \& Sociedade. 2011;14(2):89104.

[14] Guivant JS. A teoria da sociedade de risco de Ulrich Beck: entre o diagnóstico e a profecia. Estudos Sociedade e Agricultura. 2001;16:95-112.

[15] Spaargaren G. Political consumerism for sustainable consumption practices. Rethinking the commitments of citizen-consumers with environmental change. In: Santos MM, Vogt C, França JGE, Guivant JS. (Orgs.). Ciência, Tecnologia e Sociedade. Novos Modelos de Governança. Brasilia: CGEE; 2005.

[16] Jacobi P. Movimento ambientalista no Brasil. Representação social e complexidade da articulação de práticas coletivas. In: Ribeiro WC. (Org.). Patrimônio Ambiental Brasileiro. São Paulo: EDUSP; 2003.

[17] Beck U. A reinvenção da política: rumo a uma teoria da modernização reflexiva. In: Beck U, Giddens A, Lash S. (Orgs). Modernização reflexiva. São Paulo: Editora da UNESP; 1997.

[18] Collins HM, Pinch T. Golam. O que você deveria saber sobre ciência. São Paulo: Editora Unesp; 2003.

[19] Guivant JS. A governança dos riscos e os desafios para a redefiniçao da arena pública no Brasil.: In: Santos MM, Vogt C, França JGE, Guivant JS. (Orgs). Ciência, Tecnologia e Sociedade. Novos Modelos de Governança. Brasilia: CGEE; 2005.

[20] Nestle M. Food Politics. Berkley, Los Angeles, London. University of California Press; 2002.

[21] Hannigan JA. Environmental Sociology: a social constructionist perspective. London: Routlegde; 2006. 